\title{
Targeting bortezomib-induced aggresome formation using vinorelbine enhances the cytotoxic effect along with ER stress loading in breast cancer cell lines
}

\author{
KANA MIYAHARA ${ }^{1}$, HIROMI KAZAMA ${ }^{2}$, HIROKO KOKUBA ${ }^{3}$, SEIICHIRO KOMATSU ${ }^{1}$, AYAKO HIROTA ${ }^{2}$, \\ JUN TAKEMURA ${ }^{2}$, KAZUHIRO HIRASAWA ${ }^{4}$, SHOTA MORIYA ${ }^{2}$, AKIHISA ABE ${ }^{2}$, \\ MASAKI HIRAMOTO $^{2}$, TAKASHI ISHIKAWA ${ }^{1}$ and KEISUKE MIYAZAWA ${ }^{2}$ \\ Departments of ${ }^{1}$ Breast Surgery and ${ }^{2}$ Biochemistry, ${ }^{3}$ Laboratory of Electron Microscopy, and \\ ${ }^{4}$ Department of Otolaryngology (Head and Neck Surgery), Tokyo Medical University, Tokyo, Japan
}

Received June 17, 2016; Accepted August 8, 2016

DOI: $10.3892 /$ ijo.2016.3673

\begin{abstract}
The ubiquitin-proteasome and autophagy-lysosome pathways are two major self-digestive systems for cellular proteins. Ubiquitinated misfolded proteins are degraded mostly by proteasome. However, when ubiquitinated proteins accumulate beyond the capacity of proteasome clearance, they are transported to the microtubule-organizing center (MTOC) along the microtubules to form aggresomes, and subsequently some of them are degraded by the autophagy-lysosome system. We previously reported that macrolide antibiotics such as azithromycin and clarithromycin block autophagy flux, and that concomitant treatment with the proteasome inhibitor bortezomib (BZ) and macrolide enhances endoplasmic reticulum (ER) stress-mediated apoptosis in breast cancer cells. As ubiquitinated proteins are concentrated at the aggresome upon proteasome failure, we focused on the microtubule as the scaffold of this transport pathway for aggresome formation. Treatment of metastatic breast cancer cell lines (e.g., MDA-MB-231 cells) with BZ resulted in induction of aggresomes, which immunocytochemistry detected as a distinctive eyeball-shaped vimentin-positive inclusion body that formed in a perinuclear lesion, and that electron microscopy detected as a sphere of fibrous structure with some dense amorphous deposit. Vinorelbine (VNR), which inhibits microtubule polymerization, more effectively suppressed BZ-induced aggresome formation than paclitaxel (PTX), which stabilizes microtubules. Combined treatment using BZ and VNR, but not PTX, enhanced the cytotoxic effect and apoptosis induction along with pronounced ER stress loading
\end{abstract}

Correspondence to: Dr Keisuke Miyazawa, Department of Biochemistry, Tokyo Medical University, 6-1-1 Shinjuku, Shinjuku-ku, Tokyo 160-8402, Japan

E-mail: miyazawa@tokyo-med.ac.jp

Key words: breast cancer, vinorelbine, bortezomib, aggresome, ER stress such as upregulation of GRP78 and CHOP/GADD153. The addition of azithromycin to block autophagy flux in the BZ plus VNR-containing cell culture further enhanced the cytotoxicity. These data suggest that suppression of BZ-induced aggresome formation using an inhibitory drug such as VNR for microtubule polymerization is a novel strategy for metastatic breast cancer therapy.

\section{Introduction}

Breast cancer is the most common cancer, accounting for $25 \%$ of all cancer cases in females worldwide (1). Development of novel drugs, including molecular targeting for breast cancer, has improved some therapeutic outcomes. However, recurrence or metastasis of breast cancer continues to occur, resulting in 521,900 deaths annually worldwide (1). Therefore, a novel therapeutic approach to recurrent/metastatic breast cancer is an important issue. Chemotherapeutic, hormone, and molecular targeting drugs are currently used for metastatic breast cancer therapy. Anthracyclines and taxanes are considered the key chemotherapeutic drugs (2). Several recent studies focused on autophagy and paclitaxel (PTX), a wellused taxane for metastatic breast cancer therapy (3-5). Some reports indicate that PTX inhibits autophagy in breast cancer cell lines (3), whereas others indicate that autophagy promotes PTX resistance in breast cancer $(4,5)$.

The autophagy-lysosome system and the ubiquitin-proteasome system (UPS) are two major self-digestive mechanisms for cellular proteins. UPS is the selective degradation pathway for most cytoplasmic proteins, especially misfolded and shortlived proteins (6). In this process, misfolded proteins tagged with ubiquitin are selectively degraded by the $26 \mathrm{~S}$ proteasome. In contrast, macroautophagy (hereafter, autophagy) is a highly conserved self-digestive system in eukaryotic cells for degradation of long-lived proteins, as well as clearance of damaged or old organelles, including endoplasmic reticulum (ER) (7). These cellular proteins and organelles are engulfed in the double-membrane vesicle known as the autophagosome and are delivered to the lysosome for degradation $(7,8)$. In contrast with the UPS, autophagy is a bulk non-selective degradation 
system. However, recent reports found crosstalk between UPS and autophagy via docking proteins such as p62/SQSTM-1, or NBR1 (neighbor of BRCA1 gene product), in which they have both the ubiquitin-associated domain and the LC3 (Atg8)interacting lesion in their C-terminus. LC3-II (lipidated form of LC3-I) studs the inner and outer autophagosome membrane. Thus, after binding to $\mathrm{p} 62$, ubiquitinated proteins are engulfed into autophagosome through the p62-LC3-II interaction $(9,10)$. The original function of autophagy is cellular quality control of cytoplasmic components and protection from nutrient starvation by amino acid recycling. However, it is now believed that cancer cells apply this system to escape from various stresses under the hypovascular condition (11-14).

We previously reported that combined treatment using the proteasome inhibitor bortezomib (BZ) and macrolide antibiotics, which block autophagy flux, resulted in pronounced apoptosis induction, along with ER stress loading in breast cancer and multiple myeloma cells (15-17). ER stress is caused by the accumulation of misfolded or unfolded proteins inside the ER lumen. A series of cellular responses is evoked as unfolded protein responses (UPRs) such as: i) attenuation of the translation for repression of unfolded protein accumulation, ii) induction of chaperon proteins for proper refolding, and iii) exporting of unfolded proteins to outside the ER lumen, following their polyubiquitination and degradation by proteasome [ER-associated degradation (ERAD)] (18-21). However, when the stress exceeds this adaptive capacity, the cell undergoes apoptosis via induction of the proapoptotic transcription factor CHOP/GADD153 and other mechanisms (19,22-25). ER stress itself also induces autophagy directly through upregulation of GRP78, which appears to compensate ERAD-mediated degradation (26).

In addition to these cellular digestive systems, the cytoplasmic misfolded proteins aggregate and are transported to the microtubule-organizing center (MTOC) along the microtubules by the retrograde microtubule motor dynein and HDAC6 complex to form aggresomes (27-30). An aggresome is a cytoplasmic inclusion body containing misfolded and ubiquitinated protein aggregates originally described by Johnston and colleagues in 1998 (27). Aggresome formation is a protective response of a cell, which involves sequestering toxic protein species beyond the capacity of UPS clearance (28-33). Some parts of the aggresome are degraded by autophagy in an HDAC6-dependent manner (30,32). Therefore, there appears to be an integrated intracellular network for misfolded protein clearance among UPS, autophagy-lysosome system, and aggresome formation. Indeed, our previous reports confirmed that simultaneous inhibition of proteasome by BZ, autophagy flux by macrolide antibiotics, and aggresome formation using suberoylanilide hydroxamic acid (SAHA), which has the effect of HDAC6 inhibition, potently induce apoptosis accompanied with ER stress loading in breast cancer and multiple myeloma cells $(34,35)$.

In this study, we focused on the microtubule that functions as the scaffold of the intracellular trafficking pathway for protein aggregate transport to MTOC to form aggresomes. Taxanes including PTX and docetaxel, and vinca alkaloids such as vinorelbine (VNR) are widely used in metastatic breast cancer therapy (2). Taxanes have the effect of microtubule stabilization, whereas VNR has the inhibitory effect of microtubule polymerization. Therefore, we hypothesized that these treatments might have the inhibitory effect of aggresome formation along with ER stress loading upon proteasome inhibition. Here, we demonstrate that combined treatment using BZ and VNR, but not PTX, pronounces apoptosis induction in metastatic breast cancer cell lines, along with ER stress loading and inhibition of BZ-induced aggresome formation.

\section{Materials and methods}

Reagents. BZ was purchased from Selleck Chemicals (Houston, TX, USA). Azithromycin dihydrate (AZM) was purchased from Tokyo Chemical Industry (Tokyo, Japan). PTX, VNR, and colchicine were obtained from Wako Pure Chemical Industries (Osaka, Japan). BZ was dissolved in dimethyl sulfoxide (DMSO) to make stock solution at a concentration of $1 \mathrm{mM}$. AZM and PTX were dissolved in 95\% ethanol at a concentration of $5 \mathrm{mM}$ as stock solutions. VNR was dissolved in distilled water to prepare a stock solution of $1 \mathrm{mM}$. Colchicine was dissolved in $95 \%$ ethanol at a concentration of $10 \mathrm{mM}$ as stock solution.

Cell lines and culture conditions. MDA-MB-231 cells were a kind gift from Dr Keiichi Iwaya (Department of Basic Pathology, National Defense Medical College, Saitama, Japan), and MDA-MB-468 cells were obtained from the American Type Culture Collection (ATCC) (Manassas, VA, USA). A CHOP ${ }^{-/}$MEF cell line (CHOP-KO-DR) established from a 13.5-day-old $\mathrm{CHOP}^{-/-}$mouse embryo by SV-40 immortalization and a $\mathrm{CHOP}^{+/+} \mathrm{MEF}$ cell line (DR-wild-type) established by SV-40 immortalization as a control cell line for CHOP-KO-DR were obtained from ATCC. MDA-MB-231, MDA-MB-468, CHOP-KO-DR, and DR-wild-type cells were cultured in Dulbecco's modified Eagle's medium (Sigma-Aldrich, St. Louis, MO, USA) supplemented with $10 \%$ fetal bovine serum (FBS; Biowest, Kiltimagh, Ireland), penicillin $(100 \mathrm{U} / \mathrm{ml})$, and streptomycin $(100 \mu \mathrm{g} / \mathrm{ml})$. All cell lines were cultured in a humidified incubator containing $5 \% \mathrm{CO}_{2}$ and $95 \%$ air at $37^{\circ} \mathrm{C}$.

Assessment of the viable number of cells. The number of viable cells was assessed using CellTiter-Blue ${ }^{\circledR}$, a cell viability assay kit (Promega Co., Madison, WI, USA), with fluorescence measurements at $560 \mathrm{~nm}$ for excitation and $590 \mathrm{~nm}$ for emission.

Flow cytometry. For assessment of apoptosis, cells were stained with Annexin V and propidium iodide (PI) using APOPCYTO $^{\mathrm{TM}}$ Annexin V-Azami-Green Apoptosis Detection kit (MBL, code 4690, Nagoya, Japan) according to the manufacturer's instructions and subjected to flow cytometry using Attune ${ }^{\circledR}$ Acoustic Focusing Cytometer (Life Technologies, CA, USA).

Immunoblotting. Immunoblotting was performed as previously described (15). Cells were lysed with RIPA lysis buffer (Nacalai Tesque, Kyoto, Japan) supplemented with a protease and phosphatase inhibitor cocktail (Nacalai Tesque). Cellular proteins were quantified using a DC Protein assay kit of Bio-Rad (Richmond, CA, USA). Equal amounts of proteins 
were loaded onto the gels, separated by SDS-PAGE, and transferred onto Immobilon-P membranes (Millipore Corp., Bedford, MA, USA). These membranes were probed with first antibodies (Abs) such as anti-ubiquitin (P4D1) $\mathrm{mAb}$ and anti-GAPDH (6C5) mAb purchased from Santa Cruz Biotechnology, Inc. (Santa Cruz, CA, USA). Immunoreactive proteins were detected using horseradish peroxidaseconjugated second Abs and an enhanced chemiluminescence reagent (ECL) (Millipore). Densitometry was performed using a Molecular Imager ChemiDoc XRS System (Bio-Rad).

Gene expression analysis. Real-time polymerase chain reaction (PCR) for expression analysis of ER stress-related genes was performed as previously described in detail (15).

Electron microscopy. Cells were fixed with $2.5 \%$ glutaraldehyde in $0.1 \mathrm{M}$ phosphate buffer ( $\mathrm{pH}$ 7.3) for $1 \mathrm{~h}$. The samples were further fixed in $1 \%$ osmium tetroxide for $1 \mathrm{~h}$, dehydrated in graded ethanol (30-100\%), and embedded in Quetol 812 epoxy resin (Nisshin EM Co., Ltd., Tokyo, Japan). Ultrathin sections were cut using an Ultracut $\mathrm{J}$ microtome (Reichert Jung, Vienna, Austria). These sections were stained with lead nitrate and uranium acetate and subjected to electron microscopic analysis using a scanning electron microscope JEM-1200EX II (Jeol, Tokyo, Japan).

Immunofluorescence staining and confocal microscopy. MDA-MB-231 cells were seeded on 13-mm glass coverslips in a 24-well culture plate in the presence or absence of BZ, PTX, and VNR and cultured for $24 \mathrm{~h}$. Coverslips were washed twice with PBS and fixed for $15 \mathrm{~min}$ on ice in methanol. After washing twice with PBS, cells were permeabilized with $0.1 \%$ Triton X-100 in TBST for $5 \mathrm{~min}$ at room temperature. The coverslips were then washed with TBST and further incubated with TBST containing 10\% normal goat serum (NGS; Thermo Fisher Scientific, Waltham, MA, USA) for $30 \mathrm{~min}$ at room temperature for blocking nonspecific binding. Cells were incubated with a primary antibody such as mouse anti-vimentin (V9) $\mathrm{mAb}$, mouse anti-ubiquitin (P4D1) mAb, and anti-p62/ SQSTM1 (D-3) mAb (all from Santa Cruz), and diluted in TBST, $1.5 \%$ NGS, $0.1 \%$ bovine serum albumin (BSA) at $4^{\circ} \mathrm{C}$ overnight. The coverslips were washed three times for $5 \mathrm{~min}$ with TBST at room temperature and subsequently incubated with Alexa Fluor ${ }^{\circledR} 488$ conjugate-goat anti-mouse $\operatorname{IgG}(\mathrm{H}+\mathrm{L})$ secondary antibody (Thermo Fisher Scientific), diluted in TBST containing $1.5 \% \mathrm{NGS}$ and $0.1 \% \mathrm{BSA}$, for $45 \mathrm{~min}$ at $37^{\circ} \mathrm{C}$. The coverslips were washed with TBST and mounted in ProLong ${ }^{\circledR}$ Diamond Antifade Montant (Thermo Fisher Scientific). Nuclei were stained with DAPI (Sigma-Aldrich, D-9542), and the cells were imaged using a confocal laser scanning fluorescence microscope, LSM 700 (Carl Zeiss, Germany).

Assessment of aggresome by fractioning of detergent-soluble and -insoluble proteins, followed by immunoblotting with anti-ubiquitin $m A b$. Cells were lysed with Triton X-100 lysis buffer $(10 \mathrm{mM}$ Tris-HCl, $150 \mathrm{mM} \mathrm{NaCl}, 2 \%$ Triton X-100, $\mathrm{pH}$ 7.8) supplemented with a protease inhibitor cocktail (Nacalai Tesqucollectede). The lysates were centrifuged at $12,000 \mathrm{~g}$ for $30 \mathrm{~min}$ at $4^{\circ} \mathrm{C}$. The supernatant was then collected as a detergent-soluble fraction. The pellets (which contain insoluble proteins) were then resuspended in sodium dodecyl sulfate (SDS) lysis buffer (10 mM Tris- $\mathrm{HCl}, 150 \mathrm{mM} \mathrm{NaCl}$, $2 \% \mathrm{SDS}, \mathrm{pH} 7.8$ ) and sonicated for $30 \mathrm{sec}$ using a tip sonicator VP-5S (Taitec, Saitama, Japan) to prepare a detergent-insoluble fraction. All resuspended pellets and supernatants were boiled for $5 \mathrm{~min}$ in the presence of an equal volume of SDS-PAGE sample buffer (125 mM Tris-HCl, 4\% SDS, 20\% glycerol, $0.002 \% \mathrm{BPB}, \mathrm{pH} 6.8$ ), and the containing proteins were separated by $11.25 \%$ SDS-PAGE and immunoblotted with anti-ubiquitin $\mathrm{mAb}$.

Morphology assessment. After trypsinization, cell suspensions were sedimented and fixed on the slide glass using a Cytospin 4 (Thermo). Preparations were stained with May-GrünwaldGiemsa and examined using a digital microscope BZ-8100 (Keyence Co., Osaka, Japan).

Statistical analysis. All the quantitative data were expressed as mean \pm standard deviation (SD). Statistical analysis was performed with two-tailed nonpaired Student's t-test. The criterion for statistical significance was taken as $\mathrm{p}<0.05$.

\section{Results}

Combined treatment using BZ plus VNR, but not PTX enhances apoptosis induction in breast cancer cell lines. It was reported that PTX inhibited autophagy flux in breast cancer cell lines (3). We previously reported that simultaneous treatment with the proteasome inhibitor BZ and AZM, which has an inhibitory effect on autophagy flux, resulted in enhanced cytotoxicity along with ER stress loading in multiple myeloma cells (17). Therefore, we hypothesized that combined treatment using BZ and PTX instead of AZM might also enhance the cytotoxic effect in metastatic breast cancer cell lines. MDA-MB-231 and MDA-MB-468 cells were first treated with BZ alone at various concentrations for 24-72 h. Both cell lines exhibited cell growth inhibition in a dose- and time-dependent manner. Fifty percent cell growth inhibitory concentrations $\left(\mathrm{IC}_{50} \mathrm{~s}\right)$ at 48 -h exposure to $\mathrm{BZ}$ were $36.3 \mathrm{nM}$ in MDA-MB-231 cells and $10.8 \mathrm{nM}$ in MDA-MB-468 cells (Fig. 1A). The cells were then treated with PTX as well as VNR in the presence or absence of $25 \mathrm{nM} \mathrm{BZ}$ in MDA-MB-231 cells and $7.5 \mathrm{nM}$ in MDA-MB-468 cells. As illustrated in Fig. 1B, assessment of viable cells indicated significant enhancement of cell growth inhibition by combining $10 \mathrm{nM}$ PTX and $25 \mathrm{nM}$ BZ. Unexpectedly, pronounced cytotoxicity did not increase further and reached a plateau at higher concentrations of PTX up to $100 \mathrm{nM}$. In contrast with the PTX combination, VNR plus BZ resulted in more prominent enhancement of cell growth inhibition in the dose-dependent manner of VNR. This phenomenon was more pronounced with the addition of AZM in the cell culture medium. When the cells were treated with BZ and AZM in the presence of PTX or VNR, only the VNR combination exhibited considerable enhancement of cell growth inhibition in both cell lines (Fig. 1C). Flow cytometric analysis with Annexin V/PI double staining indicated a significant increase of Annexin V-positive/PI-negative cells (cells undergoing early-stage apoptosis) and Annexin V/PI double-positive cells (undergoing late-stage apoptosis) only 
$\mathbf{A}$

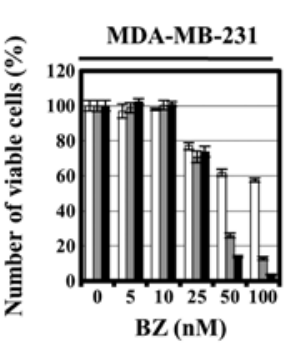

B
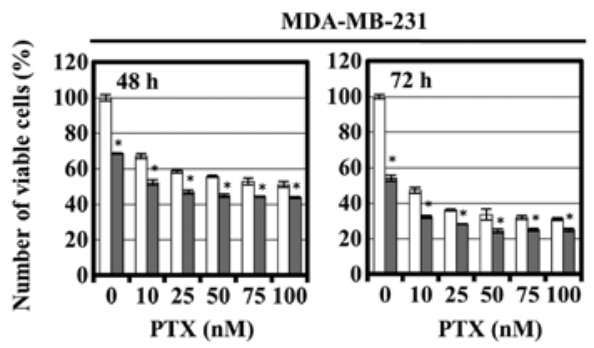

PTX (nM)
MDA-MB-231
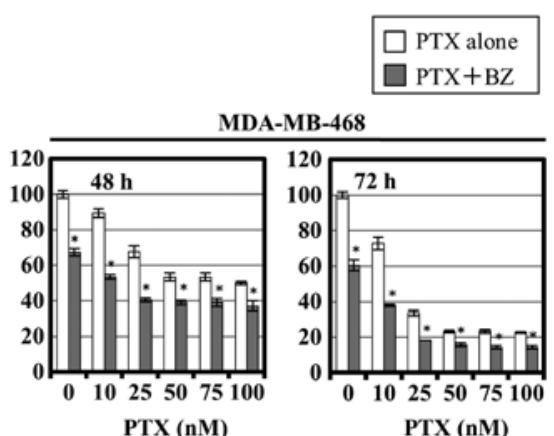

MDA-MB-468

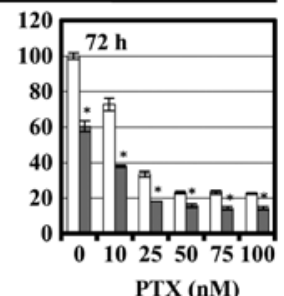

PTX (nM)

$\square$ VNR alone

$\mathrm{VNR}+\mathrm{BZ}$

MDA-MB-468

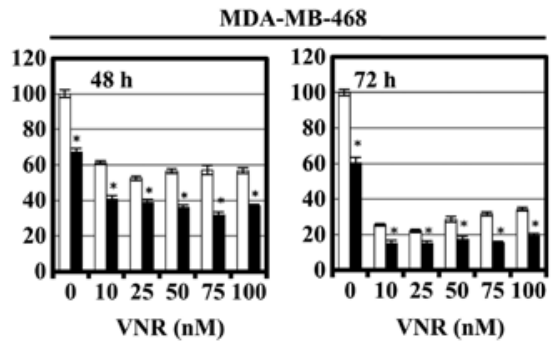

C

MDA-MB-231
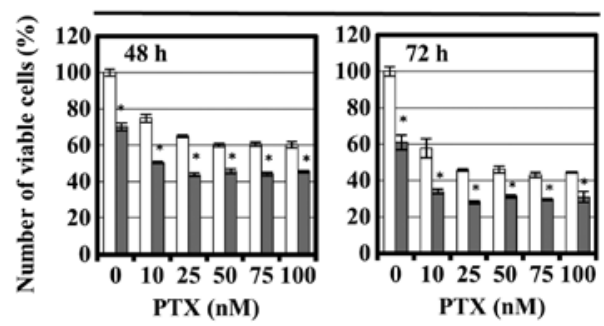

PTX (nM)
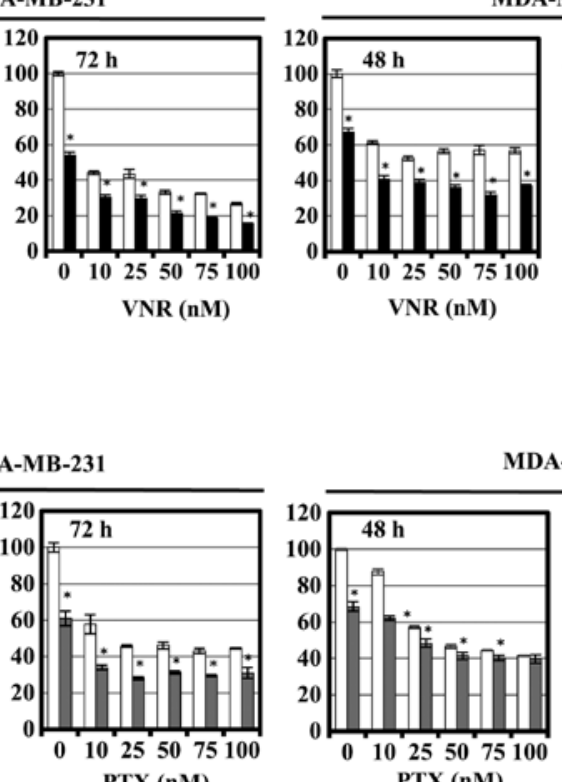

$\square$ PTX alone

$\square$ PTX+BZ+AZM

MDA-MB-468

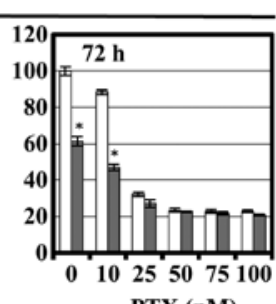

PTX (nM)

$\mathrm{VNR}$ alone

$\mathrm{VNR}+\mathrm{BZ}+\mathrm{AZM}$

MDA-MB-231
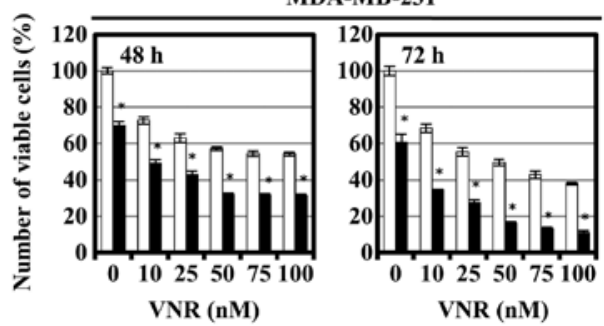

MDA-MB-468

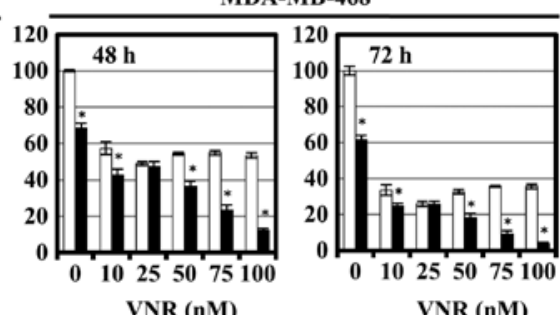

Figure 1. Cell growth inhibition and apoptosis induction of MDA-MB-231 and MDA-MB-468 cells after combined treatment using PTX or VNR and BZ in the presence or absence of AZM. (A) MDA-MB-231 and MDA-MB-468 cells were treated with BZ at various concentrations for 24,48 and 72 h. The viable cell number was assessed using CellTiter Blue assay as described in Materials and methods. (B) MDA-MB-231 and MDA-MB-468 cells were treated with PTX or VNR at various concentrations with/without BZ (25 nM for MDA-MB-231 cells and $7.5 \mathrm{nM}$ for MDA-MB-468 cells) for 48 and $72 \mathrm{~h}$. $\mathrm{P}<0.05$; PTX vs. PTX+BZ, VNR vs. VNR+BZ. (C) MDA-MB-231 and MDA-MB-468 cells were treated with PTX or VNR in the presence of BZ (25 and 5 nM) and AZM $(50 \mu \mathrm{M})$ for 48 and $72 \mathrm{~h}$. ${ }^{\mathrm{P}}<0.05$; PTX vs. PTX+BZ+AZM, VNR vs. VNR+BZ+AZM. 

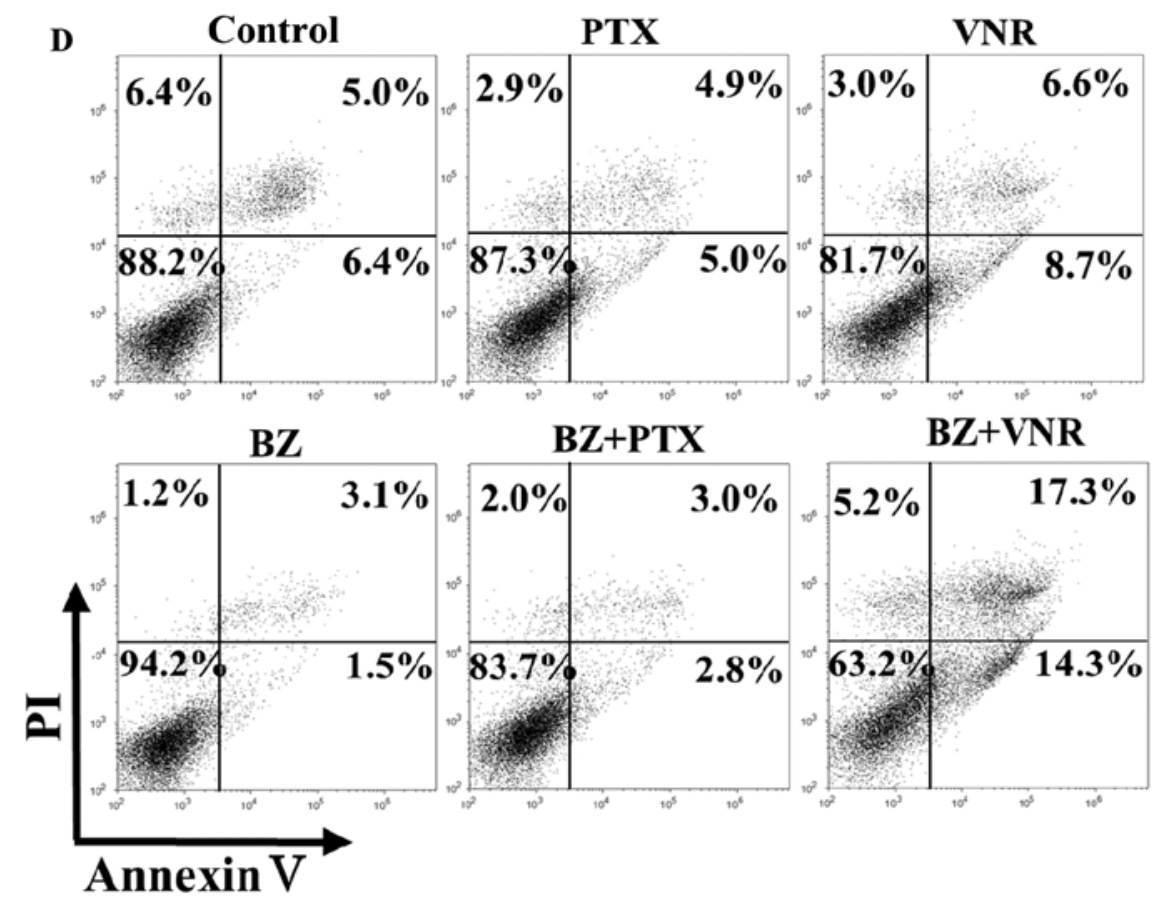

Figure 1. Continued. (D) MDA-MB-231 cells were treated with BZ (25 nM), PTX (50 nM), or VNR (50 nM) alone or a combination of BZ and PTX, or BZ and VNR for $24 \mathrm{~h}$. Flow cytometric analysis with Annexin V/PI double staining was performed. Numbers indicate the percentage of the cells in each area to the cells in whole gating.

after combined treatment using BZ plus VNR, but not using BZ plus PTX (Fig. 1D). These data indicate that VNR is superior to PTX in combination with BZ for apoptosis induction in breast cancer cell lines.

Inhibition of BZ-induced aggresome formation using VNR and PTX in MDA-MB-231 cells. Aggresome formation occurs when production of aggregation-prone misfolded protein exceeds the capacity of proteasome digestion. In aggresomes, protein aggregates are actively degraded by the autophagylysosome pathway $(29,31,35)$. Hence, we next examined whether aggresome is induced in MDA-MB-231 cells in response to proteasome inhibition by BZ. Immunocytochemistry using anti-vimentin $\mathrm{mAb}$ exhibited a single eyeball-shaped dense body in the perinuclear lesion after 24-h treatment with BZ (Fig. 2A), which appears to indicate the marker of aggresome formation at MTOC, as previously reported $(27,32)$. Although the intracellular structure of vimentin filaments changed greatly after exposure to BZ compared with untreated cells, we could detect only $20 \%$ of the spherical body-positive MDA-MB-231 cells during 24-h exposure to BZ. Extended BZ exposure time or increased BZ concentration resulted in increasing dead cells and losing optimal conditions for detecting a single spherical aggresome. Immunoblottings with anti-ubiquitin and anti-p62 mAbs exhibited the assembly of ubiquitinated proteins as well as p62 in the perinuclear lesion in response to BZ, but they were not as dense as the vimentin profile (Fig. 2A). Electron microscopy indicated that, in agreement with the spherical body stained with anti-vimentin $\mathrm{Ab}$, a different density area was observed in the perinuclear lesion surrounded by mitochondria (Fig. 2B). At higher magnification, substantial condensation of fibrous structure with some dense amorphous deposits became evident in the spherical body area. These data indicate aggresome formation in response to $\mathrm{BZ}$ treatment in MDA-MB-231 cells.

PTX inhibits microtubule depolymerization, whereas VNR inhibits microtubule polymerization $(2,3)$. As shown in Fig. 3, morphologic features at metaphase were different after PTXand VNR-treatment. Since protein aggregates are transported along the microtubules to MTOC for aggresome formation, we next assessed the inhibitory effect of PTX and VNR on the blocking efficacy of aggresome formation. As indicated in Fig. 4, both PTX and VNR inhibited aggresome formation, along with the scattering of ubiquitinated protein and p62 in the cytoplasm. Although the fibrous structure appeared to be somewhat different between PTX and VNR treatments, quantitative assessment of the efficacy of aggresome inhibition was difficult using immunocytochemistry. Therefore, we performed immunoblotting using anti-ubiquitin (P4D1) mAb to detect the polyubiquitinated proteins in detergent-soluble and detergent-insoluble fractions (Fig. 5). After treatment of MDA-MB-231 cells with BZ, polyubiquitinated proteins in the detergent-insoluble fraction, which indicate aggresome, increased (lane 12) with some increase in the detergent-soluble fraction, compared with untreated control cells. Treatment of the cells using BZ plus AZM further enhanced aggresome in the detergent-insoluble fraction (lane 16), as well as the detergent-soluble ubiquitinated-proteins (lane 6). This condition appears to indicate overflowing of the ubiquitinated proteins by simultaneous inhibition of two major protein degradation systems. It is noteworthy that ubiquitinated proteins in the soluble fraction increased more with BZ plus VNR treatment than with BZ plus PTX (lanes 7 vs. 8). The fact that treatment with VNR alone did not increase ubiquitinated proteins 

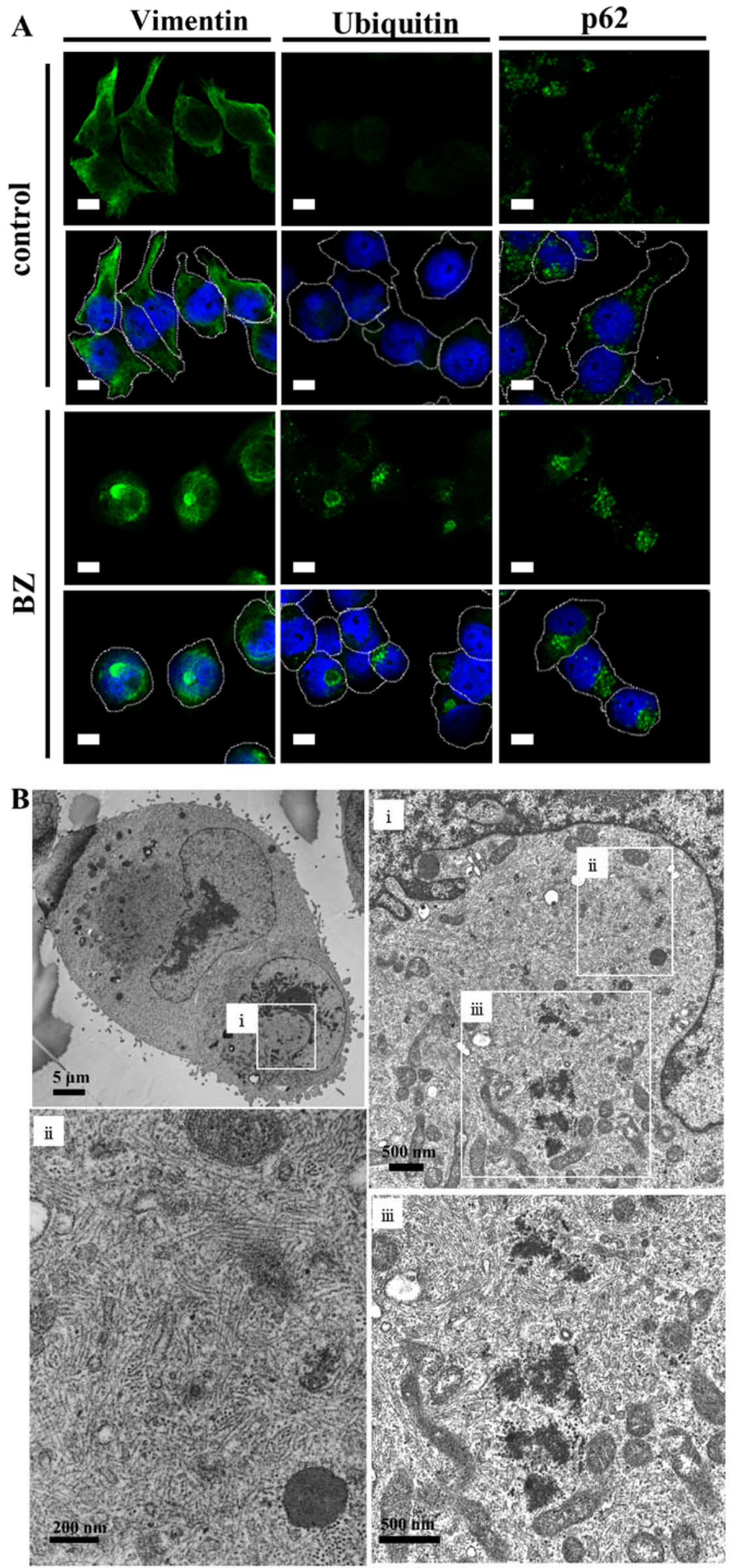

Figure 2. Aggresome formation after treatment using BZ in MDA-MB-231 cells. (A) After 24-h treatment using BZ at $25 \mathrm{nM}$, immunocytochemistry was performed using anti-vimentin $\mathrm{mAb}$, anti-ubiquitin $\mathrm{mAb}$, and anti-p62 mAb. DAPI staining indicates the position of the nucleus (blue). Dotted white line represents cell outline. Scale bar $10 \mu \mathrm{m}$. (B) Electron microscopy: MDA-MB-231 cells were treated with BZ (25 nM) for $24 \mathrm{~h}$. 

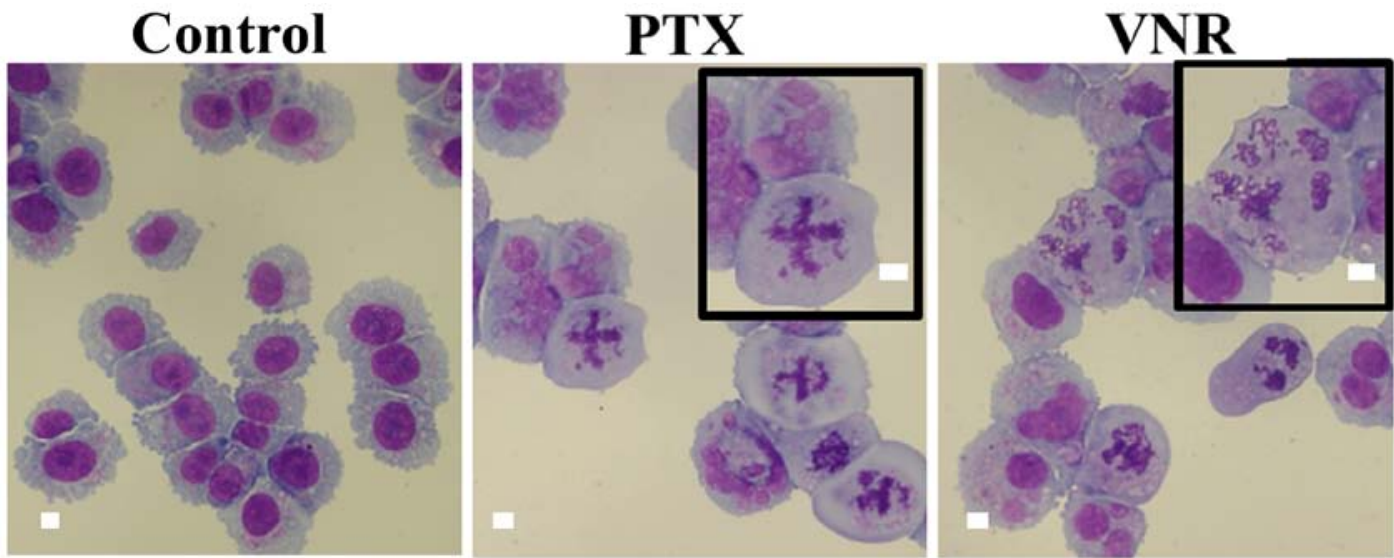

Figure 3. Comparison of morphological changes in MDA-MB-231 cells with PTX and VNR treatment. MDA-MB-231 cells were stained with May-GrünwaldGiemsa. Cells were cultured with PTX (50 nM) or VNR (50 nM) for $48 \mathrm{~h}$. Scale bar $20 \mu \mathrm{m}$.
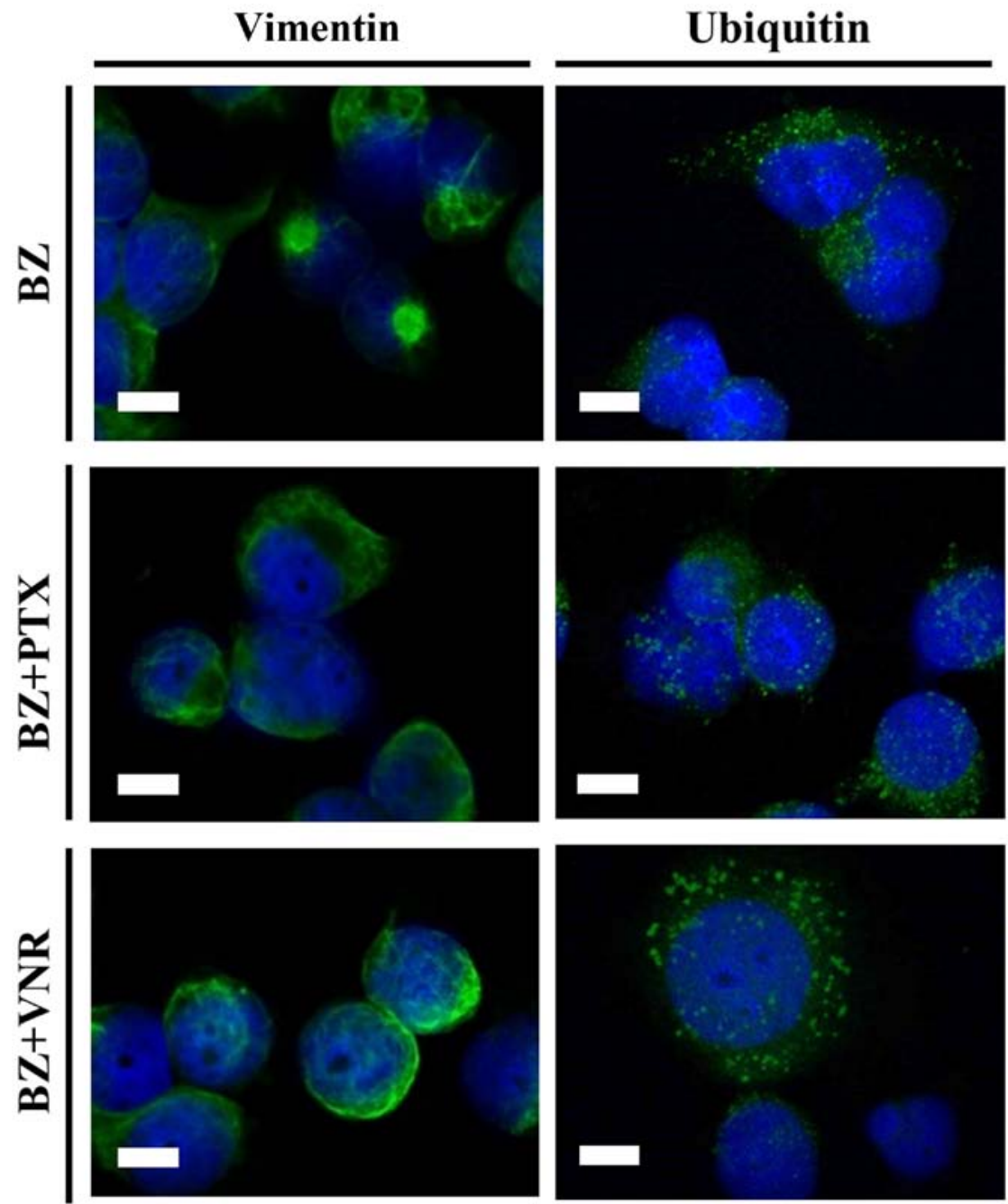

Figure 4. Inhibitory effect of VNR and PTX on BZ-induced aggresome formation in MDA-MB-231 cells. MDA-MB-231 cells were treated with BZ (25 nM) with/without either PTX $(50 \mathrm{nM})$ or VNR $(50 \mathrm{nM})$ for $24 \mathrm{~h}$. Immunocytochemistry was performed using anti-vimentin mAb, and anti-Ub mAb. DAPI staining indicates the position of the nucleus (blue). Scale bar, $10 \mu \mathrm{m}$.

in the soluble fraction (lane 5) confirms that VNR inhibits BZ-induced aggresome formation more efficiently than PTX. This phenomenon becomes more apparent in the presence of AZM for blocking autophagy flux (lanes 9 vs. 10).
Enhancement of ER stress loading after combined treatment using BZ and VNR. Our previous report indicated that blocking BZ-induced aggresome by HDAC6 inhibition using SAHA resulted in ER stress loading, which led to CHOP- 

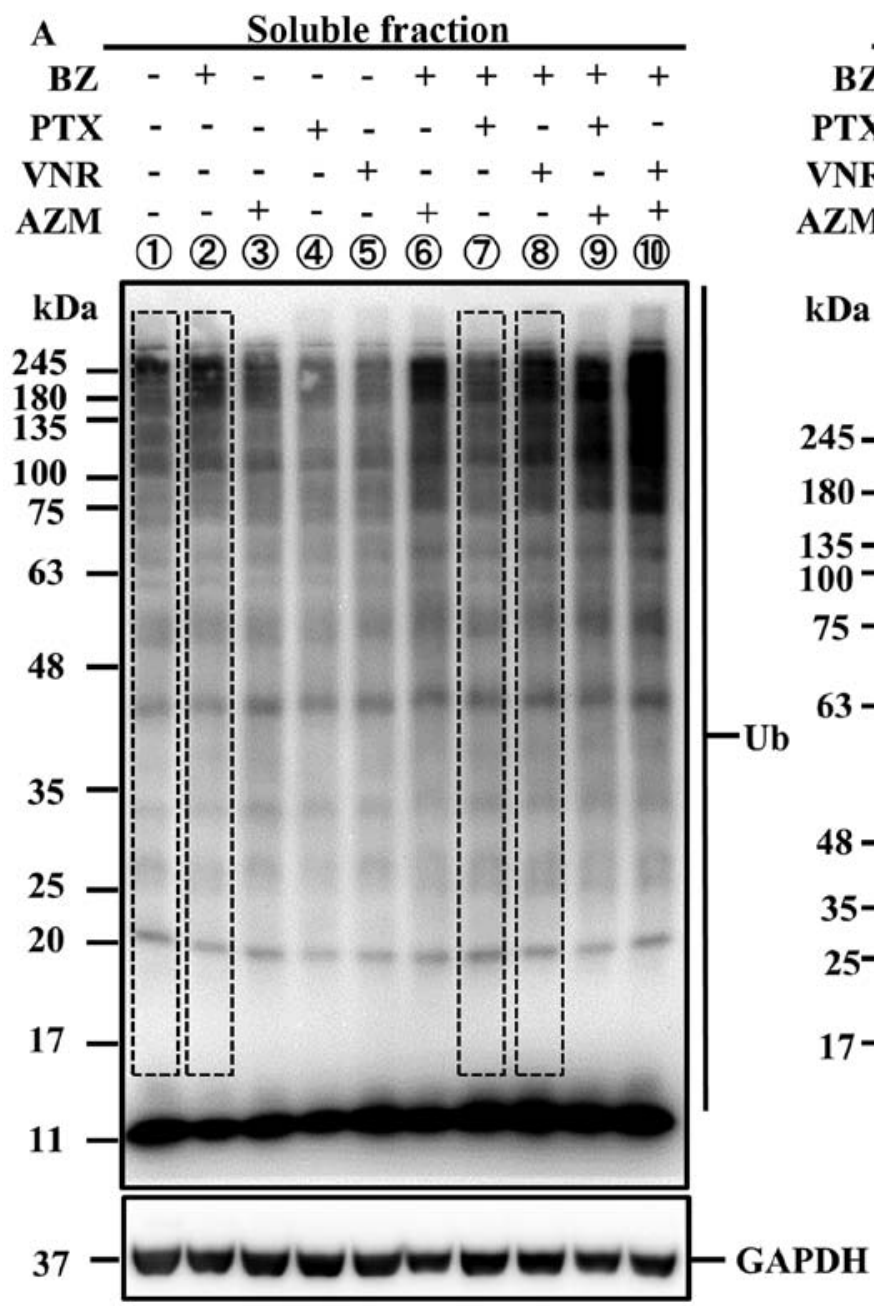

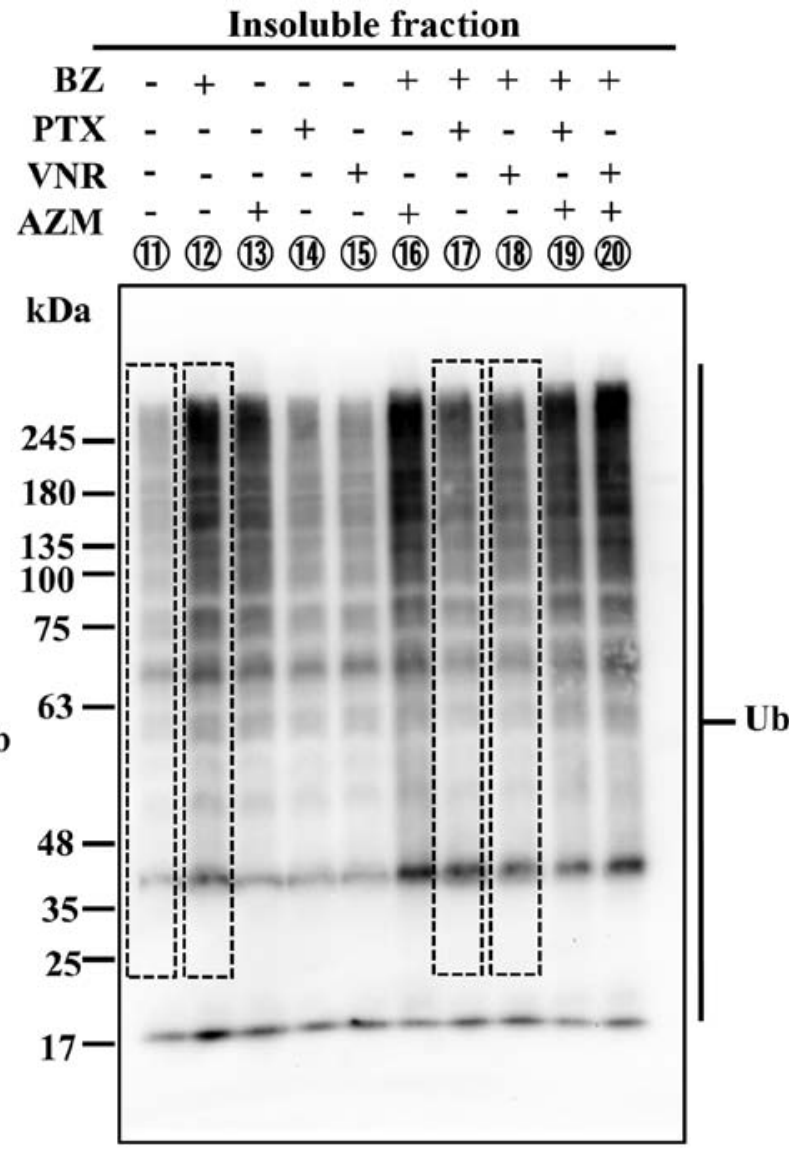

B

Soluble fraction

(1)(2)(3)(4)(5)(6)(8)(9)(10)

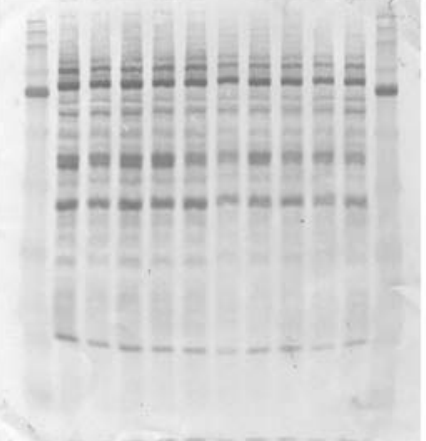

Insoluble fraction (11)(12)(13)(14)(15)(16)(11)(18)(19)(20)

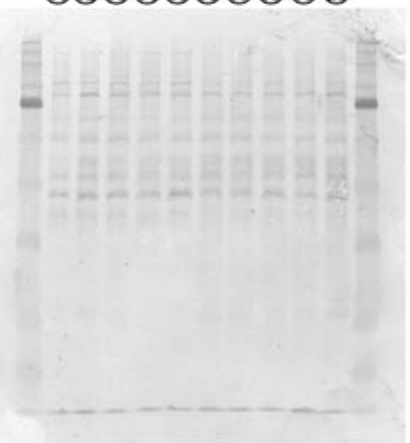

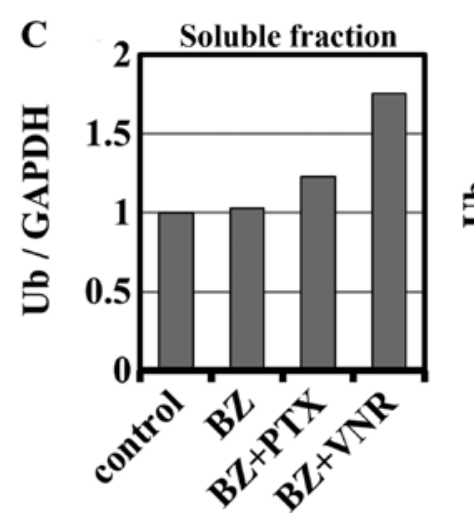

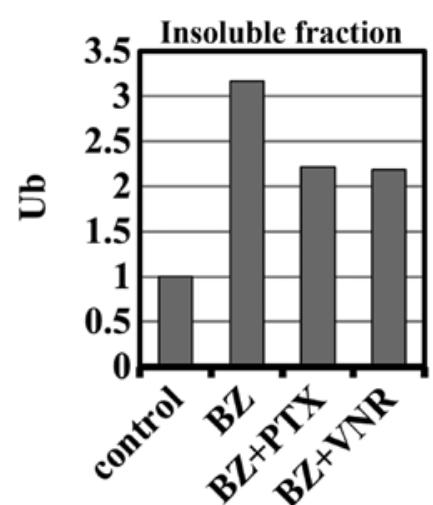

Figure 5. Assessment of aggresome inhibition by immunoblotting using anti-ubiquitin mAb. (A) MDA-MB-231 cells were treated with BZ (25 nM), AZM $(50 \mu \mathrm{M})$, PTX $(50 \mathrm{nM})$, or VNR $(50 \mathrm{nM})$ alone or two or three combinations as indicated for $48 \mathrm{~h}$. The method of preparing samples of cellular proteins for soluble and insoluble fractions is described in detail in Materials and methods. Each fractionated protein was loaded and separated by $11.25 \%$ SDS-PAGE, and immunoblotted with anti-ubiquitin-mAb. In detergent-soluble fractions, immunoblotting with anti-GAPDH mAb was performed as an internal control. (B) After immunoblotting, the transferred membrane was re-stained with Coomassie Brilliant Blue R-250 for the assessment of protein loading. (C) Densitometry of the polyubiquitinated proteins in the detergent-soluble and detergent-insoluble fractions: densitometry of the square areas denoted by the dotted line in the upper panel was performed, and the density ratios to the controls (lanes 1 and 11) were plotted. In the soluble fractions, each lane density was standardized by the density ratios to GAPDH as an internal control.

mediated apoptosis induction in myeloma and breast cancer cells $(34,35)$. Therefore, we assessed ER stress-related gene expression after combined treatment using BZ and PTX or VNR in MDA-MB-231 cells. During 48-h exposure to these reagents, real-time PCR exhibited pronounced expression of GRP78 and CHOP with combined treatment using BZ plus VNR, but not using BZ plus PTX, compared with those treated using each reagent alone (Fig. 6). Thus, the gene expression 

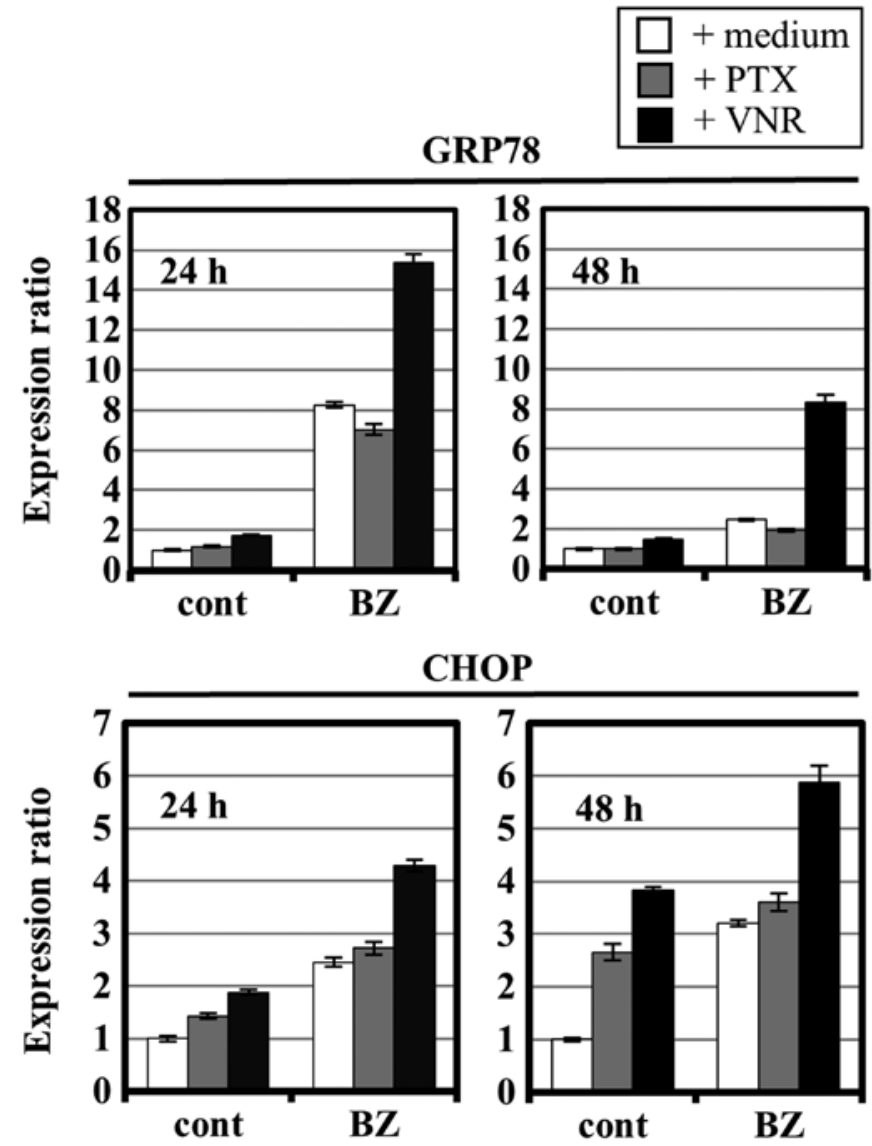

Figure 6. ER stress loading after combined treatment using BZ and PTX or VNR in MDA-MB-231 cells. MDA-MB-231 cells were treated with BZ $(25 \mathrm{nM}), \mathrm{PTX}(50 \mathrm{nM})$, or VNR $(50 \mathrm{nM})$ alone or a combination of BZ and PTX, or BZ and VNR for $24 \mathrm{~h}$ and $48 \mathrm{~h}$. Gene expression of CHOP and GRP78, which are related to ER stress loading, were assessed using real-time PCR.

profiles fit well with the result of the cell growth inhibition presented in Fig. 1B.

Since the proapoptotic transcription factor CHOP plays a central role in ER stress-related apoptosis induction $(23,25)$, we next examined whether $\mathrm{CHOP}$ is involved in pronounced cytotoxicity by combined treatment with VNR and BZ+AZM using immortalized MEF cells derived from CHOP knockout mouse. VNR enhanced BZ+AZM-induced cytotoxicity in immortalized wild-type MEF in a dose-dependent manner, whereas $\mathrm{CHOP}^{-/}$MEF exhibited less sensitivity to BZ+AZM treatment and attenuated enhanced cytotoxicity by VNR (Fig. 7). Notably, as well as breast cancer cell lines, PTX exhibited no enhanced cytotoxicity in the presence of BZ+AZM in MEF cell line (Figs. 1C and 7). These data suggest that pronounced apoptosis induction by BZ and VNR is at least partially mediated through $\mathrm{CHOP}$ induction.

\section{Discussion}

Herein, we demonstrated that VNR, which has inhibitory effect on microtubule polymerization, blocked BZ-induced aggresome formation (Fig. 5), and concomitant treatment of VNR and BZ with/without AZM markedly enhanced the cytotoxic effect and apoptosis induction, along with

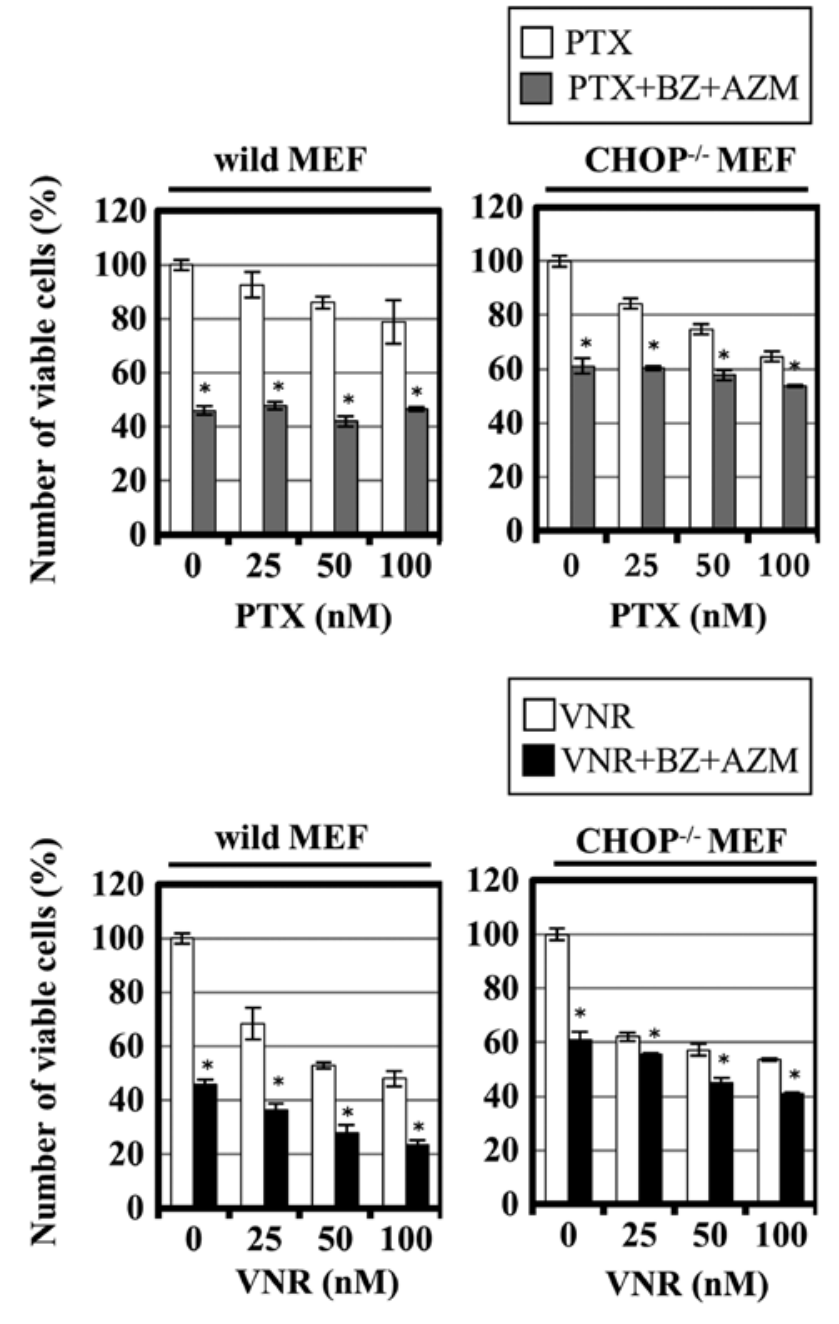

Figure 7. Involvement of $\mathrm{CHOP}$ in enhanced cytotoxicity with a combination of BZ and VNR+AZM. Cell growth inhibition of wild-type MEF cell line and $\mathrm{CHOP}^{-/}$cell line after treatment using VNR or PTX with/without BZ $(25 \mathrm{nM})+\mathrm{AZM}(50 \mu \mathrm{M})$ for $24 \mathrm{~h}$. The viable cell number was assessed using CellTiter Blue assay as described in Materials and methods. ${ }^{*} \mathrm{P}<0.05$; PTX vs. PTX+BZ+AZM, VNR vs. VNR+BZ+AZM.

pronounced ER stress loading, in metastatic breast cancer cell lines (Figs. 1 and 6). Since PTX inhibits autophagy in breast cancer cells (3), we initially expected that simultaneous inhibition of the two major digestive systems, proteasome by BZ and autophagy by PTX, would enhance ER stress-mediated apoptosis induction, as was the case with BZ plus AZM in our previous report on myeloma cells (34). However, contrary to our initial expectation, no prominent pronounced cytotoxicity was observed with the BZ and PTX combination (Fig. 1). For now, we cannot clearly explain the difference in the effects of the drugs regarding the cytotoxicity of BZ. It may be due to the pharmacological difference in disrupting microtubules (i.e., inhibition of microtubule polymerization by VNR versus microtubule stabilization by PTX) (Fig. 3). Indeed, colchicine, which has an inhibitory effect on microtubule polymerization, also exhibited enhanced cytotoxicity of BZ in MDA-MB-231 cells, like VNR (data not shown). In addition, VNR appears to be more effective for suppressing BZ-induced aggresome formation than PTX. This results in an increase of cytosolic detergent-soluble ubiquitinated proteins (Fig. 5) and enhances 
ER stress loading (Fig. 6), following ER stress-mediated apoptosis via CHOP activation (Figs. 1D and 7).

In addition to aggresome inhibition, recent studies indicated that subcellular lysosomal positioning was also affected by microtubule formation. Depolymerization of the microtubules by nocodazole resulted in the scattering of lysosomes and reduced the nutrient-dependent activation of mTORC1 (36). Proteasome failure promoted the positioning of lysosomes around the aggresome via local blocking of the microtubule-dependent transport (37). Microtubules support the assembly of pre-autophagosomal structures and mediate trafficking of autophagosomes toward lysosomes (38). Thus, perturbation of microtubules directly affects the encounter between autophagosome and lysosome to form autolysosome, leading to suppression of protein degradation by the autophagylysosome system. Microtubules also regulate mTORC1 and class III PI3K complexes, two major complexes involved in the initiation of autophagic response (39). All this evidence suggests that disrupting microtubules interrupts the digestive function of autophagy as well as aggresome formation. However, treatment using VNR or PTX alone did not increase polyubiquitinated protein in the detergent-soluble fraction, whereas AZM induced some detergent-insoluble aggresome, but far less than BZ. Thus, proteasome plays a critical role in ubiquitinated protein clearance.

Since intracellular unfolded protein aggregates are cytotoxic, aggresome is assumed to play a role in protecting cells by encapsulating these protein aggregates by vimentin filaments when unfolded proteins accumulate beyond the capacity of UPS (31,32). After 24-h exposure to BZ for proteasome inhibition, MDA-MB-231 cells exhibited an eyeball-shaped vimentin positive-inclusion body in the perinuclear lesion (Fig. 2A). This morphological feature seems to fit with the original description regarding the aggresome by Johnson et al (27): a pericentriolar membrane-free, cytoplasmic inclusion containing misfolded, ubiquitinated protein ensheathed in a cage of vimentin, a type III intermediate filament protein. However, analysis using electron microscopy indicated that this spherical body was composed mostly of fibrous structure, and electron-dense deposits in perinuclear lesions were much smaller than the typical aggresomes observed in various neurodegenerative disorders such as Parkinson's disease, Alzheimer's disease, and Huntington's disease $(27,32,39)$ (Fig. 2B). This may be due to the rapid turnover of tumor cells and their upregulated metabolic state. It was reported that BZ induced aggresome formation in pancreatic cancer cells but not in immortalized normal human pancreatic epithelial cells (40), also suggesting a higher level of protein synthesis and dependency on the proteasome degradation system for survival in cancer cells than in normal cells. In our system, MDA-MB-231 cells might undergo apoptosis in response to $\mathrm{BZ}$ before presenting the characteristic features of aggresome. However, upon proteasome inhibition by BZ, how dynamic remodeling of vimentin filaments occurs to form a perinuclear sphere body, even with insufficient amounts of protein aggregate deposits, remains unclear. Other than cellular protein accumulation followed by transport along the microtubules toward the centriole, some molecular switch may occur to initiate the aggresome formation. Vimentin filaments interact with signaling proteins such as phospholipase A2, 14-3-3 proteins, and bind to phosphorylated ERK and RhoK
$(41,42)$. A recent report indicated that vimentin C328 is essential for the binding site with zinc to lead to optimal vimentin performance in network expansion, aggresome formation, and lysosomal distribution (43). This may indicate the existence of signal recognition site(s) of vimentin to initiate conformational changes. Thus, clarification of crosstalk between proteasome and vimentin is an attractive challenge. More precise time course study is required.

In this study, we intentionally used clinically available drugs. VNR and PTX are key drugs for metastatic breast cancer therapy, whereas BZ is widely used to treat multiple myeloma. Their safety has been established, and information regarding pharmacokinetics and adverse effects has been accumulated. Thus, inhibition of BZ-induced aggresome formation using VNR could be a potent practicable combination, based on a novel concept for metastatic breast cancer patients. Furthermore, MDA-MB-231 and MDA-MB-468 cell lines used in this study have the characteristics of triplenegative breast cancer (TNBC), a subtype of tumor estrogen receptor (ER)-negative, progesterone receptor (PgR)-negative, and human epidermal receptor 2 (HER2)-negative, BZ plus VNR might be effective combination for TNBC therapy. Our data also suggest that targeting the intracellular proteostatic regulatory network among proteasome, autophagy-lysosome, and aggresome has potential for cancer therapy.

\section{Acknowledgements}

This study was supported by funds provided through a MEXTsupported program of the Strategic Research Foundation at Private Universities (S1411011, 2014-2018) from the Ministry of Education, Culture, Sports, Science and Technology of Japan; Grants-in-Aid for Scientific Research (C) from The Ministry of Education, Culture, Sports, Science and Technology (no. 26460478); and a Grant-in-Aid from Tokyo Medical University Cancer Research to K.M and a Grant-in-Aid for Young Scientist (B) from the Ministry of Education, Culture, Sports, Science and Technology of Japan (no. 26670589) to S.K.

\section{References}

1. Torre LA, Bray F, Siegel RL, Ferlay J, Lortet-Tieulent J and Jemal A: Global cancer statistics, 2012. CA Cancer J Clin 65: 87-108, 2015.

2. Runowicz CD, Leach CR, Henry NL, Henry KS, Mackey HT, Cowens-Alvarado RL, Cannady RS, Pratt-Chapman ML, Edge SB, Jacobs LA, et al: American Cancer Society/American Society of Clinical Oncology Breast Cancer Survivorship Care Guideline. J Clin Oncol 34: 611-635, 2016.

3. Veldhoen RA, Banman SL, Hemmerling DR, Odsen R, Simmen T, Simmonds AJ, Underhill DA and Goping IS: The chemotherapeutic agent paclitaxel inhibits autophagy through two distinct mechanisms that regulate apoptosis. Oncogene 32: 736-746, 2013.

4. Wen J, Yeo S, Wang C, Chen S, Sun S, Haas MA, Tu W, Jin F and Guan JL: Autophagy inhibition re-sensitizes pulse stimulationselected paclitaxel-resistant triple negative breast cancer cells to chemotherapy-induced apoptosis. Breast Cancer Res Treat 149: 619-629, 2015.

5. Liu S and Li X: Autophagy inhibition enhances sensitivity of endometrial carcinoma cells to paclitaxel. Int J Oncol 46: 2399-2408, 2015.

6. Wojcik S: Crosstalk between autophagy and proteasome protein degradation systems: Possible implications for cancer therapy. Folia Histochem Cytobiol 51: 249-264, 2013.

7. Mizushima N: Autophagy: Process and function. Genes Dev 21: 2861-2873, 2007. 
8. Levine B and Kroemer G: Autophagy in the pathogenesis of disease. Cell 132: 27-42, 2008.

9. Korolchuk VI, Menzies FM and Rubinsztein DC: Mechanisms of cross-talk between the ubiquitin-proteasome and autophagylysosome systems. FEBS Lett 584: 1393-1398, 2010.

10. Kirkin V, McEwan DG, Novak I and Dikic I: A role for ubiquitin in selective autophagy. Mol Cell 34: 259-269, 2009.

11. Degenhardt K, Mathew R, Beaudoin B, Bray K, Anderson D, Chen G, Mukherjee C, Shi Y, Gélinas C, Fan Y, et al: Autophagy promotes tumor cell survival and restricts necrosis, inflammation, and tumorigenesis. Cancer Cell 10: 51-64, 2006.

12. Mathew R, Karp CM, Beaudoin B, Vuong N, Chen G, Chen HY, Bray K, Reddy A, Bhanot G, Gelinas C, et al: Autophagy suppresses tumorigenesis through elimination of p62. Cell 137: 1062-1075, 2009.

13. Karantza-Wadsworth V, Patel S, Kravchuk O, Chen G, Mathew R, Jin S and White E: Autophagy mitigates metabolic stress and genome damage in mammary tumorigenesis. Genes Dev 21: $1621-1635,2007$

14. Guo JY, Chen HY, Mathew R, Fan J, Strohecker AM, KarsliUzunbas G, Kamphorst JJ, Chen G, Lemons JM, Karantza V, et al: Activated Ras requires autophagy to maintain oxidative metabolism and tumorigenesis. Genes Dev 25: 460-470, 2011.

15. Kawaguchi T, Miyazawa K, Moriya S, Ohtomo T, Che XF, Naito $M$, Itoh $M$ and Tomoda $A$ : Combined treatment with bortezomib plus bafilomycin A1 enhances the cytocidal effect and induces endoplasmic reticulum stress in U266 myeloma cells: Crosstalk among proteasome, autophagy-lysosome and ER stress. Int J Oncol 38: 643-654, 2011.

16. Komatsu S, Miyazawa K, Moriya S, Takase A, Naito M, Inazu M, Kohno N, Itoh M and Tomoda A: Clarithromycin enhances bortezomib-induced cytotoxicity via endoplasmic reticulum stress-mediated CHOP (GADD153) induction and autophagy in breast cancer cells. Int J Oncol 40: 1029-1039, 2012.

17. Moriya S, Che XF, Komatsu S, Abe A, Kawaguchi T, Gotoh A, Inazu M, Tomoda A and Miyazawa K: Macrolide antibiotics block autophagy flux and sensitize to bortezomib via endoplasmic reticulum stress-mediated $\mathrm{CHOP}$ induction in myeloma cells. Int J Oncol 42: 1541-1550, 2013.

18. Meusser B, Hirsch C, Jarosch E and Sommer T: ERAD: The long road to destruction. Nat Cell Biol 7: 766-772, 2005.

19. Hetz C: The unfolded protein response: Controlling cell fate decisions under ER stress and beyond. Nat Rev Mol Cell Biol 13: 89-102, 2012

20. Smith MH, Ploegh HL and Weissman JS: Road to ruin: Targeting proteins for degradation in the endoplasmic reticulum. Science 334: 1086-1090, 2011

21. Brodsky JL: Cleaning up: ER-associated degradation to the rescue. Cell 151: 1163-1167, 2012.

22. Sano R and Reed JC: ER stress-induced cell death mechanisms. Biochim Biophys Acta 1833: 3460-3470, 2013.

23. Oyadomari S and Mori M: Roles of CHOP/GADD153 in endoplasmic reticulum stress. Cell Death Differ 11: 381-389, 2004.

24. Tabas I and Ron D: Integrating the mechanisms of apoptosis induced by endoplasmic reticulum stress. Nat Cell Biol 13 184-190, 2011

25. Verfaillie T, Garg AD and Agostinis P: Targeting ER stress induced apoptosis and inflammation in cancer. Cancer Lett 332: 249-264, 2013

26. Li J, Ni M, Lee B, Barron E, Hinton DR and Lee AS: The unfolded protein response regulator GRP78/BiP is required for endoplasmic reticulum integrity and stress-induced autophagy in mammalian cells. Cell Death Differ 15: 1460-1471, 2008.
27. Johnston JA, Ward CL and Kopito RR: Aggresomes: A cellular response to misfolded proteins. J Cell Biol 143: 1883-1898, 1998

28. Kawaguchi Y, Kovacs JJ, McLaurin A, Vance JM, Ito A and Yao TP: The deacetylase HDAC6 regulates aggresome formation and cell viability in response to misfolded protein stress. Cell 115: 727-738, 2003.

29. Olzmann JA and Chin LS: Parkin-mediated K63-linked polyubiquitination: A signal for targeting misfolded proteins to the aggresome-autophagy pathway. Autophagy 4: 85-87, 2008.

30. Lee JY, Koga H, Kawaguchi Y, Tang W, Wong E, Gao YS, Pandey UB, Kaushik S, Tresse E, Lu J, et al: HDAC6 controls autophagosome maturation essential for ubiquitin-selective quality-control autophagy. EMBO J 29: 969-980, 2010.

31. Rodriguez-Gonzalez A, Lin T, Ikeda AK, Simms-Waldrip T, $\mathrm{Fu} \mathrm{C}$ and Sakamoto KM: Role of the aggresome pathway in cancer: Targeting histone deacetylase 6 -dependent protein degradation. Cancer Res 68: 2557-2560, 2008.

32. Kopito RR: Aggresomes, inclusion bodies and protein aggregation. Trends Cell Biol 10: 524-530, 2000.

33. Brüning A and Jückstock J: Misfolded proteins: From little villains to little helpers in the fight against cancer. Front Oncol 5: 47, 2015.

34. Moriya S, Komatsu S, Yamasaki K, Kawai Y, Kokuba H, Hirota A, Che XF, Inazu M, Gotoh A, Hiramoto M, et al: Targeting the integrated networks of aggresome formation, proteasome, and autophagy potentiates ER stress-mediated cell death in multiple myeloma cells. Int J Oncol 46: 474-486, 2015.

35. Komatsu S, Moriya S, Che XF, Yokoyama T, Kohno N and Miyazawa K: Combined treatment with SAHA, bortezomib, and clarithromycin for concomitant targeting of aggresome formation and intracellular proteolytic pathways enhances ER stress-mediated cell death in breast cancer cells. Biochem Biophys Res Commun 437: 41-47, 2013.

36. Yu L, McPhee CK, Zheng L, Mardones GA, Rong Y, Peng J, Mi N, Zhao Y, Liu Z, Wan F, et al: Termination of autophagy and reformation of lysosomes regulated by mTOR. Nature 465: 942-946, 2010

37. Zaarur N, Meriin AB, Bejarano E, Xu X, Gabai VL, Cuervo AM and Sherman MY: Proteasome failure promotes positioning of lysosomes around the aggresome via local block of microtubuledependent transport. Mol Cell Biol 34: 1336-1348, 2014.

38. Mackeh R, Perdiz D, Lorin S, Codogno P and Poüs C: Autophagy and microtubules - new story, old players. J Cell Sci 126: 1071-1080, 2013

39. Olzmann JA, Li L and Chin LS: Aggresome formation and neurodegenerative diseases: Therapeutic implications. Curr Med Chem 15: 47-60, 2008.

40. Nawrocki ST, Carew JS, Pino MS, Highshaw RA, Andtbacka RH, Dunner K Jr, Pal A, Bornmann WG, Chiao PJ, Huang P, et al: Aggresome disruption: A novel strategy to enhance bortezomibinduced apoptosis in pancreatic cancer cells. Cancer Res 66: 3773-3781, 2006.

41. Helfand BT, Chang L and Goldman RD: Intermediate filaments are dynamic and motile elements of cellular architecture. J Cell Sci 117: 133-141, 2004.

42. Perlson E, Michaelevski I, Kowalsman N, Ben-Yaakov K, Shaked M, Seger R, Eisenstein M and Fainzilber M: Vimentin binding to phosphorylated Erk sterically hinders enzymatic dephosphorylation of the kinase. J Mol Biol 364: 938-944, 2006.

43. Pérez-Sala D, Oeste CL, Martínez AE, Carrasco MJ, Garzón B and Cañada FJ: Vimentin filament organization and stress sensing depend on its single cysteine residue and zinc binding. Nat Commun 6: 7287, 2015 